\title{
A vida não pode ser feita só de sonhos: reflexões sobre publicidade e alimentação saudável
}

\author{
Life cannot consist of dreams alone: \\ reflections on advertising and a healthy diet
}

Andréa Siliveste Brasil Villagelim ${ }^{1}$

Shirley Donizete Prado ${ }^{1}$

Ricardo Ferreira Freitas ${ }^{2}$

Maria Claudia da Veiga Soares Carvalho ${ }^{1}$

Claudia Olsieski da Cruz ${ }^{1}$

Juliana Klotz ${ }^{1}$

Gesseldo de Brito Freire ${ }^{1}$
${ }^{1}$ Programa de Pós-

Graduação em Alimentação

Nutrição e Saúde, Instituto

de Nutrição, Núcleo de

Estudos sobre Cultura e

Alimentação, Universidade do Estado do Rio de Janeiro.

Rua São Francisco Xavier

524/12.007 Bloco D,

Maracanã. 20559-900 Rio

de Janeiro RJ.

shirley.prado@yahoo.com.br

${ }^{2}$ Programa de Pós-

Graduação em

Comunicação, Faculdade de

Comunicação Social,

Centro de Educação e

Humanidades,

Universidade do Estado do

Rio de Janeiro.
Abstract In this essay we present some thoughts on advertising and a healthy diet in the contemporary world, where consumption plays a highly relevant role. We seek to emphasize two aspects, among many others yet to be explored in the scientific literature in the food and nutritional field: the hegemony of the biomedical paradigm and the fragmentation of human life when advertising campaigns associate food with the idea of a healthy diet. We believe that we cannot merely live through advertisements in which our desires are triggered constantly and where the world is only dreams and the main goal is to sell more and earn more, even using some strategies for dissemination of biomedical and nutritional information. In our opinion, the merger between diet and health, i.e. a healthy diet, must involve enlightenment of the individual including information on quality in the context of social life in order to achieve the ideal of happiness. Individuals whose identities are fully formed both in dreams and reality can boldly seek knowledge and think about themselves in the world context, as well as zeal for their diet and health.

Key words Feeding habits, Healthy diet, Communication, Advertising, Consumption, Culture
Resumo Neste ensaio apresentamos algumas reflexões sobre publicidade e alimentação saudável no mundo contemporâneo onde o consumo exerce papel de grande relevância. Buscamos enfatizar dois aspectos, entre tantos outros ainda por serem explorados na literatura científica do campo alimentar-nutricional: a hegemonia do paradigma biomédico e a fragmentação da vida humana quando campanhas publicitárias anunciam alimentos associando-os à ideia de alimentação saudável. Consideramos que não podemos viver somente como naquela publicidade onde nossos desejos são acionados, sem limites, onde mundo é só de sonhos e o objetivo principal é vender mais e lucrar mais, ainda que para isso se tenha feito uso de estratégias de disseminação de algumas informações de cunho biomédico-nutricional. O encontro entre alimentação e saúde, ou seja, alimentação saudável, deve pressupor, no nosso entendimento, a valorização da ação do sujeito, inclusive por meio de informações qualificadas e contextualizadas na vida social de modo a que se possa desenhar projetos de felicidade. Um sujeito fortalecido em sua identidade, íntegro e total que, entre sonhos e concretudes, pode ousar a buscar o conhecer e o pensar sobre si mesmo no mundo, sobre sua alimentação e sua saúde.

Palavras-chave Práticas alimentares, Alimentação saudável, Comunicação, Publicidade, Consumo, Cultura 


\section{Introdução}

Neste ensaio apresentamos algumas reflexões sobre publicidade e alimentação no mundo contemporâneo onde o consumo exerce papel de grande relevância sobre a cultura, a economia, a alimentação, a nutrição, a saúde e a doença, entre outras dimensões da sociedade. Mais especificamente, voltamo-nos para a ideia de alimentação saudável que, a partir do final do século $\mathrm{XX}^{1}$, tem sido colocada como uma das estratégias para a promoção da saúde ${ }^{2}$.

Reconhecendo o quão importante é propiciar condições para que a população receba informações adequadas sobre relações entre processos complexos como alimentação-nutrição e saúdedoença, voltamo-nos, aqui, para dois aspectos que consideramos problemáticos, entre outros ainda por serem explorados: a hegemonia do paradigma biomédico e a fragmentação da vida humana que se mostram marcantes no encontro entre alimentação saudável e publicidade no cenário da globalização, do tempo acelerado, do individualismo sem precedentes, do fast food... no qual quase tudo pode ser consumido, inclusive com euforia e excessos - ou no mundo que Lipovetsky e Charles denominam hipermodernidade ${ }^{3}$.

Estudos sobre consumo são recentes na literatura nacional. Barbosa ${ }^{4}$ considera que a nossa sociedade exalta o valor da produção, tendo-a como, simbolicamente, superior ao consumo. O trabalho e a produção são, frequentemente, considerados como aqueles que dignificam o homem, edificam uma nação e geram riquezas, sendo parte valorizada da identidade do ser humano e possuindo caráter social relevante. O consumo, por sua vez, tende a ser visto como expressão do individualismo e da superficialidade. Estas perspectivas parecem estar na origem da, ainda, reduzida produção acadêmica brasileira sobre o mundo do consumo em oposição à forte predominância dos estudos sobre a produção e o trabalho. Mesmo nesse cenário intelectual relativamente adverso, o consumo na modernidade ou na hipermodernidade de Lipovetisky - está cada vez mais em evidência, despertando interesse das Ciências Humanas e Sociais e de diversos outros campos de conhecimento, que têm se voltado para temas como consumismo, perfil do consumidor, porque consumir, o que consumir e sociedade consumista ${ }^{5-9}$.

O consumo remete a indagações a respeito da realidade do indivíduo, cercado mais por sensações e percepções do que pela razão. Campanhas publicitárias buscam criar mecanismos para atin- gir esse mundo de sonhos e despertar paixões no ser humano, no mais das vezes, reduzido a consumidor. Everardo Rocha ${ }^{10}$ afirma que a narrativa publicitária, ao construir diante de nossos olhos um mundo imaginário, longe de fazê-lo de modo ingênuo, opera com profunda seriedade em busca da realização de seus objetivos empresariais e lucrativos. Ao mesmo tempo, permitenos reconhecer nossas próprias vidas, contadas através de fragmentos que revelam nosso modo de ser, nossos afetos e, sobretudo, nossas práticas de consumo. Há, assim, um contraste entre o que é discutido na campanha publicitária e o que se passa em nossa realidade ou entre: ficção lá dentro e realidade aqui fora (grifos do autor).

Bourdieu $^{11}$, discutindo o jornalismo na televisão, alerta para sérios problemas aí existentes e que podem implicar em alienação dos sujeitos e sua submissão cada vez maior aos interesses mercadológicos dominantes na sociedade capitalista. Ele destaca o poder de influência do campo jornalístico, definindo-o como um espaço social estruturado, um campo de forças - há dominantes e dominados, há relações constantes, permanentes, de desigualdade, que se exercem no interior desse espaço - que é também um campo de lutas para transformar ou conservar esse campo de forças. Nessa linha, poderíamos pensar nas campanhas publicitárias obedecendo ao poder dos índices de audiência e expressando relações de poder e de interesse vinculadas aos anúncios e produtos.

Essa publicidade de enfoque mercadológico, que investe em esferas emocionais e oníricas, participa ativamente da construção de pilares que sustentam essa hipermodernidade contemporânea. Esse universo dos sonhos, construído na esfera da publicidade e de seus mecanismos estratégicos, atravessa diversos processos da vida humana, entre eles a alimentação e a saúde.

\section{Alimentação saudável, a hegemonia do paradigma biomédico e a fragmentação da vida}

Lidar com a ideia de alimentação saudável significa reconhecer a polifonia que a caracteriza. A título de ilustração, registramos que Alimentação é conceito que, com frequência, é tomado por Nutrição, inclusive nos meios acadêmicos, embora envolva, este último, o lugar da Natureza - o comer para a sobrevivência e o nutrir para alcançar o corpo biológico fortalecido para enfrentar e vencer as doenças - enquanto que, diferentemente, o primeiro refere ao universo Social, onde está o alimentar dos gostos, ritos e símbo- 
los, sentidos e significados que somente os seres humanos podem conferir e, aí, construir identidade, cultura e sociedade ${ }^{12-17}$. Assim, também, saúde e doença dizem respeito a fenômenos distintos e, no mais das vezes, tratados como o mesmo ${ }^{18-20}$. Em vários espaços, incluindo o mundo da publicidade, alimentação e saúde são encontradas lado a lado, como se fossem nutrição e doença.

Nesta virada de milênio, iniciativas governamentais conferiram institucionalidade a algumas perspectivas relativas à ideia de alimentação saudável através da Estratégia Global para a Promoção da Alimentação saudável, Atividade Física e Saúde, lançada em 2003 pela Organização Mundial da Saúde ${ }^{21}$. Sob o título "Promoção da Alimentação saudável”, o Ministério da Saúde brasileiro propõe, nos dias atuais, ações no âmbito da Política Nacional de Alimentação e Nutrição, nos seguintes termos:

"Promoção da Alimentação Saudável (PAS) é uma das linhas de trabalho da Coordenação Geral da Política Nacional de Alimentação e Nutrição e tem como objetivo apoiar os estados e os municípios brasileiros no desenvolvimento de ações e abordagens para a promoção da saúde e a prevenção de doenças relacionadas à alimentação e nutrição, tais como anemia, hipovitaminose A, distúrbios por deficiência de iodo (DDIs), desnutrição, obesidade, diabetes, hipertensão, câncer, entre outras"22.

Sua operacionalização se dá, por exemplo, através do Guia Alimentar para a População Brasileira ${ }^{23}$ que, emblematicamente, inicia-se com uma caixa de texto, em destaque, onde se lê: Deixe que a alimentação seja o seu remédio e o remédio a sua alimentação (Hipócrates).

Diez Garcia ${ }^{24}$ destaca a forte associação, no mundo moderno, da ideia de alimentação saudável com a hegemônica visão nutricional pautada em recomendações científicas relativas à ingestão de nutrientes necessários às atividades fisiológicas, bioquímicas do corpo biológico humano. Nas palavras da autora, dieta é o termo que melhor traduz o enfoque atual de alimentação saudável; ou seja, a associação da alimentação com a prevenção de doenças crônico-degenerativas, conferindo-lhe um caráter de medicalização $0^{25}$. Isso fica bem expresso quando a alimentação é identificada como causadora das doenças e a sua composição química é hipervalorizada, como nos diz Lifschitz ${ }^{26}$ :

O rótulo do alimento, indicando sua composição, transforma-se, assim, no equivalente a uma bula ("indicações de uso e contraindica- ções"), e o alimento, desagregado em componentes e funções, em medicamento, e, enquanto tal, sujeito à fórmula "serve para...".

São abordagens construídas a partir do paradigma biomédico, de cunho biologicista, tecnicista, intervencionista, que ignoram - ou, quando muito, mencionam, sem efetivamente valorizar ou dimensionar de forma adequada - o papel dos aspectos econômicos, sociais, políticos, culturais e psíquicos na construção social de fenômenos situados no âmbito da saúde e da alimentação. Trata-se de uma visão que reduz a comida - aqui entendida como "alimento simbolizado" e mediador de relações sociais, situado, assim, na ordem da cultura e da vida em sociedade $^{14,27}$ - aos seus nutrientes e demais componentes químicos.

$\mathrm{Na}$ esteira dessas práticas discursivas, ideias sobre alimentação saudável vêm se capilarizando nos espaços de formação de técnicos especialistas, nos serviços de saúde e entre a população em geral, o que podemos, ao menos em parte, atribuir a sua veiculação nos meios de comunicação. Programas de rádio e televisão, matérias jornalísticas nas mais diversas mídias, peças de entretenimento nos cinemas e na Internet, assim como a publicidade, cumprem papéis de veículos de informações que se apresentam, de algum modo, como promotores de práticas de alimentação saudável.

$\mathrm{O}$ uso de informações nutricionais em campanhas publicitárias de muitos produtos alimentícios, centradas na prevenção de riscos de desenvolvimento de patologias por meio de ênfase em sua composição química, atesta essa perspectiva biomédica acima aludida ${ }^{25,28,29}$. Cabe aqui destacar o crescente fenômeno do uso, em vários alimentos industrializados, de selos de aprovação de sociedades científicas situadas no campo da saúde (muitos dos quais associando o produto a expressões como alimento saudável, alimentação saudável ou vida saudável) reforçando, assim, sua função medicamentosa ${ }^{30}$. A saúde, por esses caminhos, fica reduzida a um ideal de inexistência de patologias, a alimentação tratada como técnica de evitação de doenças e a vida humana subordinada às normas estabelecidas por técnicos especialistas ${ }^{20,31}$

Por esse modelo de difusão de informação científico-nutricional, aliada ao objetivo de aumento das vendas e dos lucros, cada alimento é apresentado isoladamente: uns para emagrecer, outros para fazer o intestino funcionar, outros para prevenir ou tratar doenças do coração... compondo um oceano de fragmentos que, por sua vez, dialogam com vários medicamentos, es- 
tes também e frequentemente, veiculando informações, muitas vezes questionáveis, sobre doenças $^{32}$. Há ainda que se considerar que informações pontuais, parciais, meias-verdades fazem parte das campanhas publicitárias, podendo, inclusive, induzir a práticas alimentares que resultam em adoecimento da população ${ }^{33-36}$.

Toda a complexidade que marca a alimentação-nutrição em suas relações com a saúde-doença é, muitas vezes, reduzida pela publicidade (em cada anúncio, filme ou embalagem) a uma versão pontual desses processos, a flashs de sonhos e de informações parciais. Rocha ${ }^{10}$, em ensaio sobre representações da mulher na publicidade, enfatiza a fragmentação que despedaça sua identidade.

"Da análise de mulher construída dentro dos anúncios emerge a imagem de uma individualidade em que o corpo - e não o espaço interno - é o que importa. O corpo é o termo marcado como expressão do ser e como objeto de uso. Mas não é apenas isso. $\mathrm{O}$ corpo feminino que a publicidade revela é fragmentado. Sofre um processo em que a unidade se perde e as partes prevalecem sobre o todo. A mulher dentro do anúncio existe, sobretudo, aos pedaços - seio, pé, perna, pele, rosto, unha, mão, nádega, olho, lábio, cílio, coxa e o que mais se puder destacar como um quebracabeça invertido, cujas peças se desencaixam, escondendo a figura que nunca se forma. Essa imagem do corpo, e corpo aos pedaços, não pode sustentar o indivíduo como totalidade".

Podemos construir, comparativamente a esta concepção de mulher em pedaços, alguma correspondência com a alimentação que emerge das construções publicitárias. Uma alimentação-nutrição atomizada e descontextualizada; sendo nossa comida fragmentada, o que restaria de nós, senão pedaços de um ser humano irreconhecível? Ficamos, assim, silenciados porque a voz ativa pressupõe um ser total, que se alimenta por inteiro, corpo e alma, biológico e simbólico, natureza e sociedade. Seguimos sendo o que consumimos; agora, porém, despedaçados e fracos ${ }^{37}$.

A pulverização da alimentação se expressa, então, através da sucessão de alimentos e mundos que nos são apresentados a cada momento. Produtos que ganham humanidade através da publicidade ${ }^{10}$ a nos dizer quem somos, sem que tenhamos lugar ativo nesse mundo de sonhos de final feliz, cuja construção escapa à nossa ação. Transitando de referências de identidade estável do passado para o presente de múltiplas possibilidades e escolhas que caracterizam a hipermodernidade, assistimos crescer as ofertas de pro- dutos que identificam um eu em permanente mudança de vestimentas, de objetos, de entretenimentos, de gostos, de comidas... num processo de geração de inseguranças, vulnerabilidade. Andrade e $\mathrm{Bosi}^{38}$ já alertavam para consequências preocupantes desses macrofenômenos sobre as subjetividades e os valores culturais.

"Uma fragmentação simbólica advém da insustentabilidade desse processo, da perda de valores culturais que dão referência à construção de subjetividades. A importação de modelos globais, em todas as dimensões da vida humana, pulveriza a dimensão simbólica, de forma violenta, transformando os modos de produção, de hábitos, de valores, e outros, promovendo um desenraizamento cultural, gerando um mundo de incertezas e de riscos produzidos, o qual se desdobra na perda da liberdade e da identidade humana."

Ora passamos a ser saudáveis quando comemos o biscoito que teria sido feito com cereais integrais, rico em fibras ou pobre em outro nutriente simbolizado como maléfico nalguma campanha publicitária; em outro momento, nossas vidas ficam mais saudáveis quando bebemos um determinado refrigerante ou somos as mães a garantir vida saudável se o oferecemos aos nossos filhos, transformados por sua vez em potências energéticas inigualáveis ao consumirem tal cereal matinal cheio de vitaminas, de minerais e de outras estruturas químicas cujo segredo industrial jamais será revelado. Ao diluir a alimentação em inúmeros alimentos isolados ou em práticas alimentares parciais situadas em distintos contextos oníricos, essa publicidade nos afasta de referências importantes de constituição de bases que valorizam ações críticas do ser humano como sujeito ativo e atomiza nossas vidas, sujeitandonos, sistematicamente. Tomando-nos por objeto, distancia-nos do poder de olhar e refletir criticamente sobre o mundo em que vivemos e de tentar construir uma vida baseada em uma busca efetiva do bem estar comum, da cidadania, da justiça, da felicidade individual e coletiva. E, por esses caminhos, desaparece o ser humano mergulhado na vida social, para (res)surgir reduzido a um consumidor individualizado e descontextualizado, mergulhado num oceano de produtos apresentados como saudáveis a serem consumidos cada vez mais, mais, mais e mais...

\section{Considerações finais}

Longe de esgotar o tema, neste ensaio realizamos, apenas e tão somente, uma primeira apro- 
ximação com o intuito de colocá-lo em discussão a partir de uma perspectiva distinta daquelas que enfatizam sua dimensão nutricional ou os riscos epidemiológicos de adoecer a ele associados. É dentro deste limite que o texto se encerra. Adotamos uma postura assumidamente estrita, no sentido da crítica a algumas limitações e problemas decorrentes de práticas que produtores de alimentos em associação com agências de publicidade vêm construindo em torno da ideia de alimentação saudável que, por sua vez, vem sendo correntemente disseminada a partir do paradigma biomédico como técnica de prevenção de doenças. Consideramos que não podemos viver somente como naquela publicidade onde nossos desejos são acionados, sem limites, sem restrições, onde mundo é só de sonhos, o contexto é lúdico, tudo é possível e o objetivo principal é vender mais e lucrar mais, ainda que para isso se tenha feito uso de estratégias de disseminação de algumas informações de cunho biomédico-nutricional. Como também não podemos aceitar unicamente a concretude expressa na dimensão biológica do alimento reduzido à função de sobrevivência e de ação contra doenças.

Distintamente, entendemos saúde como um conjunto de investimentos individuais e coletivos que nos possibilitam encarar as doenças como fenômeno que faz parte da vida e que inclui outras ordens além do corpo biológico como a dignidade, a cidadania ${ }^{39}$ e, conforme Ayres $^{40}$, a felicidade.

"Com base na Hermenêutica Filosófica, de Hans-Georg Gadamer, e na Teoria da Ação Co- municativa, de Jurgen Habermas, procuramos demonstrar que os conceitos de saúde e doença se referem a interesses práticos e instrumentais, respectivamente, na elaboração racional de experiências vividas de processos de saúde-doença-cuidado. Defende-se que o obscurecimento desses distintos interesses decorre da "colonização da nossa experiência vivida" pelas estruturas conceituais das ciências biomédicas. Aponta-se para a necessidade de contrapor, a essa tendência, a reconstrução chamada humanizadora das práticas de saúde, tornando-nos todos, profissionais, serviços, programas e políticas de saúde, mais sensíveis, críticos e responsivos aos sucessos práticos sempre visados por meio e para além de qualquer êxito técnico no cuidado em saúde (Grifos do autor)" ${ }^{\prime 40}$.

Entendemos que a alimentação percorre muitos lugares da vida (humana e planetária), que vão desde a historicidade e da construção social do que é comestível, ou seja, dos valores que identificam a comida, passando pela organização da sua produção até seu consumo. O desfecho biológico desse processo corresponde à esfera do nutricional, expresso no corpo de cada indivíduo.

O encontro entre alimentação e saúde, ou seja, alimentação saudável, deve pressupor, no nosso entendimento, a valorização da ação do sujeito, inclusive por meio de informações qualificadas e contextualizadas na vida social de modo a que se possa desenhar projetos de felicidade. Um sujeito fortalecido em sua identidade, íntegro e total que, entre sonhos e concretudes, possa ousar a buscar o conhecer e o pensar sobre si mesmo no mundo, sobre sua alimentação e sua saúde.

\section{Colaboradores}

ASB Villagelim, SD Prado, RF Freitas, CO Cruz, MCVS Carvalho, J Klotz e GB Freire participaram de todas as etapas do estudo, desde sua concepção até a produção da versão final do texto.

\section{Agradecimentos}

Nossos agradecimentos por bolsas e auxílios financeiros recebidos das instituições UERJ, FAPERJ, CAPES e CNPq. 


\section{Referências}

1. Azevedo E. Reflexões sobre riscos e o papel da ciência na construção do conceito de alimentação saudável. Rev Nutr 2008; 21(6):717-723.

2. Santos LAS. Educação alimentar e nutricional no contexto da promoção de práticas alimentares saudáveis. Rev Nutr 2005; 18(5):681-692.

3. Lipovetsky G, Charles S. Le temps hipermodernes. Paris: Editions Grasset; 2004.

4. Barbosa L. Sociedade de consumo. Rio de Janeiro: Jorge Zahar; 2004.

5. Barbosa L, Campbell C. Cultura, consumo e identidade. Rio de Janeiro: FGV; 2006.

6. Baudrillard J. A sociedade de consumo. Rio de Janeiro: Elfos Editora; 1995.

7. Bauman Z. Modernidade líquida. Rio de Janeiro: Jorge Zahar; 2001.

8. Featherstone M. Cultura de consumo e pós-modernismo. São Paulo: Studio Nobel; 1995.

9. Giddens A. As consequências da modernidade. São Paulo: Unesp; 1991.

10. Rocha E. Representações do consumo: estudos sobre a narrativa publicitária. Rio de Janeiro: Mauad; 2006.

11. Bourdieu P. Sobre a televisão. Rio de Janeiro: Jorge Zahar; 1997.

12. Carvalho MCVS, Luz MT, Prado SD. Comer, alimentar e nutrir: categorias analíticas instrumentais no campo da pesquisa científica. Cien Saude Colet 2011; 16(1):155-163.

13. Bosi MLM, Prado SD. Alimentação e Nutrição em Saúde Coletiva: constituição, contornos e estatuto científico. Cien Saude Colet 2011; 16(1):7-17.

14. Klotz J, Prado SD, Carvalho MCVS, Ornelas TFS, Oliveira PF. Alimentação e cultura como campo científico no Brasil. Physis 2010; 20(2):413-442.

15. Canesqui AM, Diez Garcia RW, organizadoras. Antropologia e Nutrição: um diálogo possível. Rio de Janeiro: Fiocruz; 2005.

16. Lévi-Strauss C. O cru e o cozido. São Paulo: Cosac \& Naify; 2004.

17. DaMatta R. O que faz do brasil, Brasil? Rio de Janeiro: Rocco; 1993.

18. Canguilhem G. Le normal et le pathologique. Paris: PUF Quadrige; 2005.

19. Foucault M. La naissance de la clinique. Paris: PUF; 2005.

20. Camargo Jr KR. Biomedicina, saber e ciência: uma abordagem crítica. São Paulo: Hucitec; 2003.

21. Organização Mundial de Saúde (OMS). Estrategia mundial sobre régimen alimentario, actividad fisica $y$ salud. [Online] 2003. [acessado 2011 jul 09]. Disponível em: http://www.who.int/dietphysicalactivity/strategy/eb11344/strategy_spanish_web.pdf

22. Brasil. Ministério da Saúde (MS). [Online] [acessado: 2011 ago 14]. Disponível em: http://nutricao. saude.gov.br/pas.php

23. Brasil. Ministério da Saúde (MS). Guia Alimentar para a População Brasileira. [site na Internet] 2006. [acessado 2011 ago 10]. Disponível em: http://189. $28.128 .100 /$ nutricao/docs/geral/guia_alimentar _conteudo.pdf

24. Diez Garcia RW. Reflexos da globalização na cultura alimentar: considerações sobre as mudanças na alimentação urbana. Rev Nutr 2003; 16(4):483-492.
25. Conrad P. The medicalization of society. Baltimore: The Johns Hopkins Press; 2007.

26. Lifschitz J. Alimentação e cultura: em torno ao natural. Physis 2001; 7(2):69-83.

27. Canesqui AM, Diez Garcia RW. Ciências Sociais e Humanas nos Cursos de Nutrição. In: Canesqui AM, Diez Garcia RW, organizadoras. Antropologia e Nutrição: um diálogo possível. Rio de Janeiro: Editora Fiocruz; 2005. p. 255-274.

28. Villagelim ASB, Prado SD. Algumas reflexões sobre marketing televisivo: o olhar de nutricionistas sobre um filme de alimento industrializado. Ceres 2008; 3(1):29-41.

29. Cruz CO. Vendendo modos saudáveis de alimentação e de vida: reflexões a partir de uma campanha publicitária de refrigerante [dissertação]. Rio de Janeiro (RJ): Universidade do Estado do Rio de Janeiro; 2011.

30. Vilagellim ASB. A vida não pode ser feita só de sonhos: reflexões sobre alimentação saudável a partir da publicidade de uma linha de biscoitos industrializados [dissertação]. Rio de Janeiro (RJ): Universidade do Estado do Rio de Janeiro; 2009.

31. Sfez L. A saúde perfeita: crítica de uma nova utopia. São Paulo: Loyola; 1996.

32. Sayd JD, Nascimento AC. Ao Persistirem os sintomas, o médico deverá ser consultado. Isto é regulação? Physis 2005; 15(2):305-328.

33. Instituto Brasileiro de Defesa do Consumidor (IDEC). Além da conta. Revista do IDEC 2009; fevereiro:16-21.

34. Lobanco CM, Vedovato GM, Cano C, Bastos DHM. Fidedignidade de rótulos de alimentos comercializados no município de São Paulo, SP. Rev Saude Publica 2009; 42(3):499-505.

35. Silva AS, Dias MRM, Ferreira TAPC. Rotulagem de alimentos para lactentes e crianças de primeira infância. Rev Nutr 2008; 21(2):185-194.

36. Monteiro CA, Levy RB, Claro RM, Castro IRR, Cannon G. A new classification of foods based on the extent and purpose of their processing. Cad Saude Publica 2010; 26(11):2039-2049.

37. Fischler C. Gastro-nomia y gastro-anomia: sabiduría del cuerpo y crisis biocultural de la alimentación contemporânea. In: Contreras J, organizador. Alimentación y cultura: necessidades, gustos y costumbres. Barcelona: Universitat de Barcelona $\mathrm{Pu}-$ blicaciones; 1995. p. 9-26.

38. Andrade A, Bosi MLM. Mídia e subjetividade: impacto no comportamento alimentar feminino. Rev Nutr 2003; 16(1):117-25.

39. Minayo MCS, Hartz ZMA, Buss P. Qualidade de vida e saúde: um debate necessário. Cien Saude Colet 2000; 5(1):7-18.

40. Ayres, JR. Uma concepção hermenêutica de saúde. Physis 2007; 17(1):43-62.

Apresentado em 05/09/2011

Aprovado em 19/01/2012

Versão final apresentada em 26/01/2012 